\title{
Sonication effect on foam properties of egg white
}

\author{
DÁVID NAGY ${ }^{1 *}$ (D), VIKTÓRIA ZSOM-MUHA ${ }^{1}$, CSABA NÉMETH $^{2}$ and \\ JÓZSEF FELFÖLDI ${ }^{1 *}$ (10
}

${ }^{1}$ Department of Physics and Control, Faculty of Food Science, Hungarian University of Agriculture and Life Sciences, Budapest, Hungary

${ }^{2}$ Capriovus Kft., 2317 Szigetcsép, Hungary

\section{CONFERENCE FULL PAPER}

Received: June 8, 2021 Accepted: July 6, 2021

Published online: August 3, 2021

(C) 2021 The Author(s)

\begin{abstract}
The aim of this study was to determine the effect of ultrasound treatment on foaming properties of egg white. The samples were sonicated at $20 / 40 \mathrm{kHz}$ and $180 / 300 \mathrm{~W}$ equipment power $(3.7 / 6.9 \mathrm{~W}$ absorbed power) for 30, 45 and 60 minutes. Foam capacity had been increased by $25 \%$ due to sonication at $40 \mathrm{kHz}$ and $6.9 \mathrm{~W}$ absorbed power for 60 minutes. This phenomenon may be caused by the homogenization effect of ultrasound and protein exposure of hydrophobic groups that improve the adsorption of protein onto the air/water interfacial molecules. It is found that frequency and duration of the treatment have no significant impact on the changes in foam capacity, only the absorbed power. On the other hand, foam stability had been decreased during the ultrasonic treatment. We can assume that sonication decreases the potential difference between the dispersed particles and the dispersion medium and this may be the cause of the collapse of the foam structure due to ultrasound treatment. In this case frequency, treatment time, and the absorbed power had a significant effect on the stability.
\end{abstract}

\section{KEYWORDS}

ultrasonic treatment, egg white, foam properties

\footnotetext{
*Corresponding authors. E-mail: Nagy.David.15@hallgato.uni-szie.hu, felfoldi.jozsef@uni-mate.hu
} 


\section{INTRODUCTION}

Egg white possesses multiple functional properties, such as foaming, gelling and emulsifying and is widely used in the food industry (Hidas et al., 2021; Singh \& Ramaswamy, 2015). Due to the excellent foaming properties, it is a common ingredient in cakes and desserts. To provide a desirable texture and quality in such food products it is crucial for the food industry to improve the foaming properties of egg white (Duan et al., 2017).

The foaming formation is mostly influenced by the structure of the contained proteins. During the industrial thermal processes these proteins can be altered, leading to undesirable functionality loss (Chen \& Ma, 2020). Using ultrasound treatment offers an application for the food industry to modify the functional properties of food proteins in a more favorable direction.

There are studies dealing with the topic of the effect of ultrasound treatment on foaming properties of egg white, but there are some conflicting observations.

Arzeni et al. (2012) found that sonication of egg white on $20 \mathrm{kHz}$ and $750 \mathrm{~W}$ equipment power ( $4.7 \mathrm{~W}$ absorbed power) for $20 \mathrm{~min}$ can alter the foaming properties. In the study, they concluded that the foam capacity and the stability were decreased due to the treatment.

On the other hand, Stefanovic et al. (2017) reported that the foaming stability and foaming capacity had been increased due to sonication on $20 \mathrm{kHz}$ and $34 \mathrm{~W}$ absorbed power for 220 minutes. In Gelvez-Ordonez' et al. (2009) study it is reported that sonication on $40 \mathrm{kHz}$ and $80 \mathrm{~W}$ for 5-10 min enhances the foam capacity, but the same treatment for 15 min resulted in a decreasing capacity. They also found that the foam stability had been decreased during the sonication regardless of the treatment time.

This is in good accordance with Sheng's study (Sheng et al., 2018). They concluded that sonication $(20 \mathrm{kHz}, 90,120,240,360$ and $480 \mathrm{~W}$ equipment power for $10 \mathrm{~min})$ significantly improved the foaming ability with a slight decline in foaming stability.

In these studies, they use different ultrasound treatment parameters that can cause these conflicting observations. Although they agree that sonication has a significant effect on the foaming properties of egg white and it seems that depending on the treatment parameters the foaming properties can have an increasing or a decreasing trend.

The purpose of this study is to inspect the sonication effect on the foaming properties of egg white to take a stand on this topic and determine the importance of the treatment parameters on these properties' changes that may explain the cause of the previous diverse findings.

\section{MATERIALS AND METHODS}

\section{Egg white samples}

A total of $7 \mathrm{~L}$ of egg white were used for this experiment, provided by Capriovus Kft. (Szigetcsép, Hungary). The product was made of "A" classified (589/2008/EC regulation) homogenized and pasteurized fresh hen eggs. The egg white samples were stored at $0-4{ }^{\circ} \mathrm{C}$ in $1 \mathrm{~L}$ jugs before the measurement.

\section{Ultrasound treatment}

To determine the effect of ultrasound treatment on foaming properties an ultrasonic bath (HBM Machines, Netherlands) was used. The equipment is capable of delivering up to $300 \mathrm{~W}$ of power 
Table 1. Sample groups by treatment parameters

\begin{tabular}{lccc}
\hline Group & Frequency & Power & Duration \\
\hline A & $20 \mathrm{kHz}$ & $180 \mathrm{~W}$ & $30,45,60 \mathrm{~min}$ \\
$\mathrm{~B}$ & $40 \mathrm{kHz}$ & $180 \mathrm{~W}$ & $30,45,60 \mathrm{~min}$ \\
$\mathrm{C}$ & $20 \mathrm{kHz}$ & $300 \mathrm{~W}$ & $30,45,60 \mathrm{~min}$ \\
$\mathrm{D}$ & $40 \mathrm{kHz}$ & $300 \mathrm{~W}$ & $30,45,60 \mathrm{~min}$ \\
$\mathrm{~K}$ & - & - & - \\
\hline
\end{tabular}

at $20 / 40 \mathrm{kHz}$ frequency. Depending on the applied treatment parameters, the samples were separated into $4+1$ groups depending on the frequency and equipment power (Table 1). These groups (except control group) were separated into three more subgroups based on the duration of the treatment.

After homogenization, $180 \mathrm{~mL}$ of egg white was poured into $200 \mathrm{~mL}$ glass container for each group. To ensure sonic conductivity the ultrasonic equipment was filled up with $16 \mathrm{~L}$ of tap water and the containers were put into this media. In order to avoid thermal impact on foaming properties an external cooling system was built to keep the temperature at low $\left(18{ }^{\circ} \mathrm{C}\right)$ temperature during the whole treatment. Untreated samples were subjected to the same temperature conditions as the sonicated ones.

The power, absorbed by the samples was measured in a preliminary experiment according to the heat increasing rate (Nagy et al., 2021).

\section{Determination of foaming properties}

For assessing foaming properties, foam capacity (how much foam can be created with whipping) and foam stability were measured. Thirty $\mathrm{mL}$ of egg white sample were poured into $150 \mathrm{~mL}$ beaker. The mass of the samples was measured by a digital scale (Radwag, WLC 2/2a) with $0.01 \mathrm{~g}$ readability. The samples then were whipped in the beaker with a hand mixer (Bosh MFQ36400, $450 \mathrm{~W})$ on the highest rotational speed $(\sim 1,300 \mathrm{rpm})$ at room temperature for 5 minutes. After whipping, the propeller was immediately removed from the beaker and the height of the foam was measured. The volume of the foam was calculated by the following equation:

$$
V=\pi^{*} r^{2} * h,
$$

where $V$ is the volume of the foam, $r$ is the radius of the beaker and $h$ is the height of the foam.

In order to determine the foam stability a glass funnel was attached to the beaker and turned upside down (Fig. 1) to separate the static drainage. After $1 \mathrm{~h}$, the mass of the obtained defoamed egg white was measured. The measurements were done in triplicates.

\section{Data analysis}

To evaluate the effect of each treatment parameter on foam capacity and foam stability ANOVA is one of the mostly used method. However, the observed data is not normally distributed, which is crucial for such statistical test. Alternatively, Kruskal-Wallis test, a non parametric test, can be used if the data does not have normal distribution. The null hypothesis of this test is that the median of the studied groups is the same. In other words, it can be tested whether there is a difference between the medians of the populations belonging to each compared groups. 


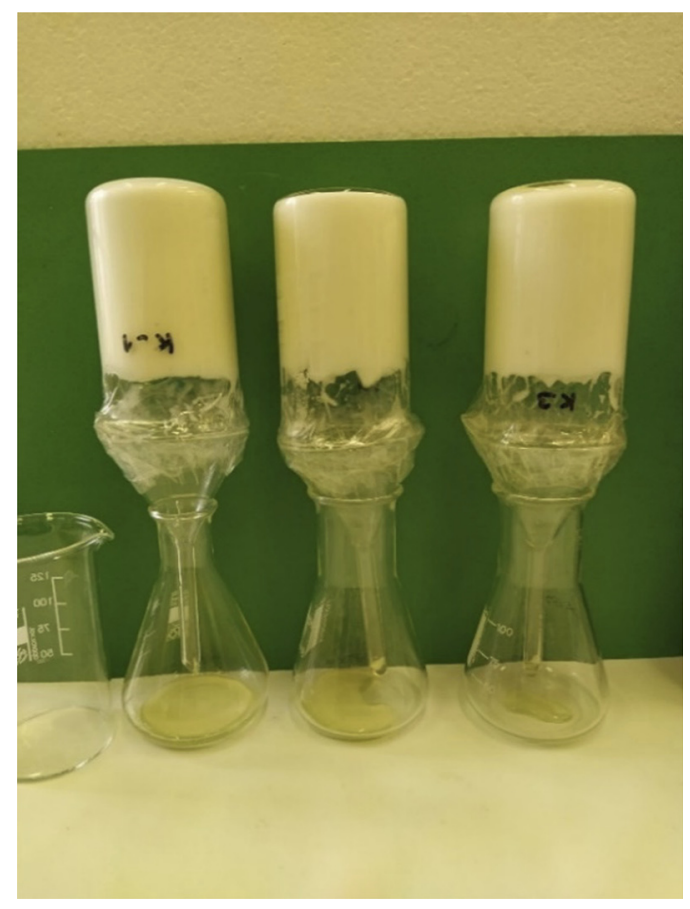

Fig. 1. Measurement setting to determine foam stability

The statistical analysis was carried out using SPSS statistics 25 (IBM, Armonk, New York, United States of America).

\section{RESULTS AND DISCUSSION}

The data shows that whipping the egg white results on average four times of foam in volume. The highest observed volume was $149.23 \mathrm{~mL}$, which was from egg white treated at $40 \mathrm{kHz}$ and $300 \mathrm{~W}$ for 60 minutes. Compared to control groups this means that sonication at this level can enhance the foam capacity by $25 \%$.

Based on the graphical analysis of the volumes (Fig. 2) it can be said that the frequency and the duration of the treatment does not affect the foaming capacity significantly. Although the higher absorbed power results visibly more foam.

The significance levels, according to Kruskal-Wallis test (frequency -0.354 , duration -0.403 , and absorbed power - 0.000) also support that the only parameter that affects the foam capacity is the treatment power.

These results are in a good accordance with studies reporting that ultrasound can enhance the foam capacity (Jambrak et al., 2008; Stefanovic et al., 2017). This phenomenon can be due to the homogenization effect of ultrasound and this treatment leading also to protein exposure of hydrophobic groups that improve the adsorption of protein onto the air/water interfacial molecules (Mirmoghtadaie et al., 2016). 

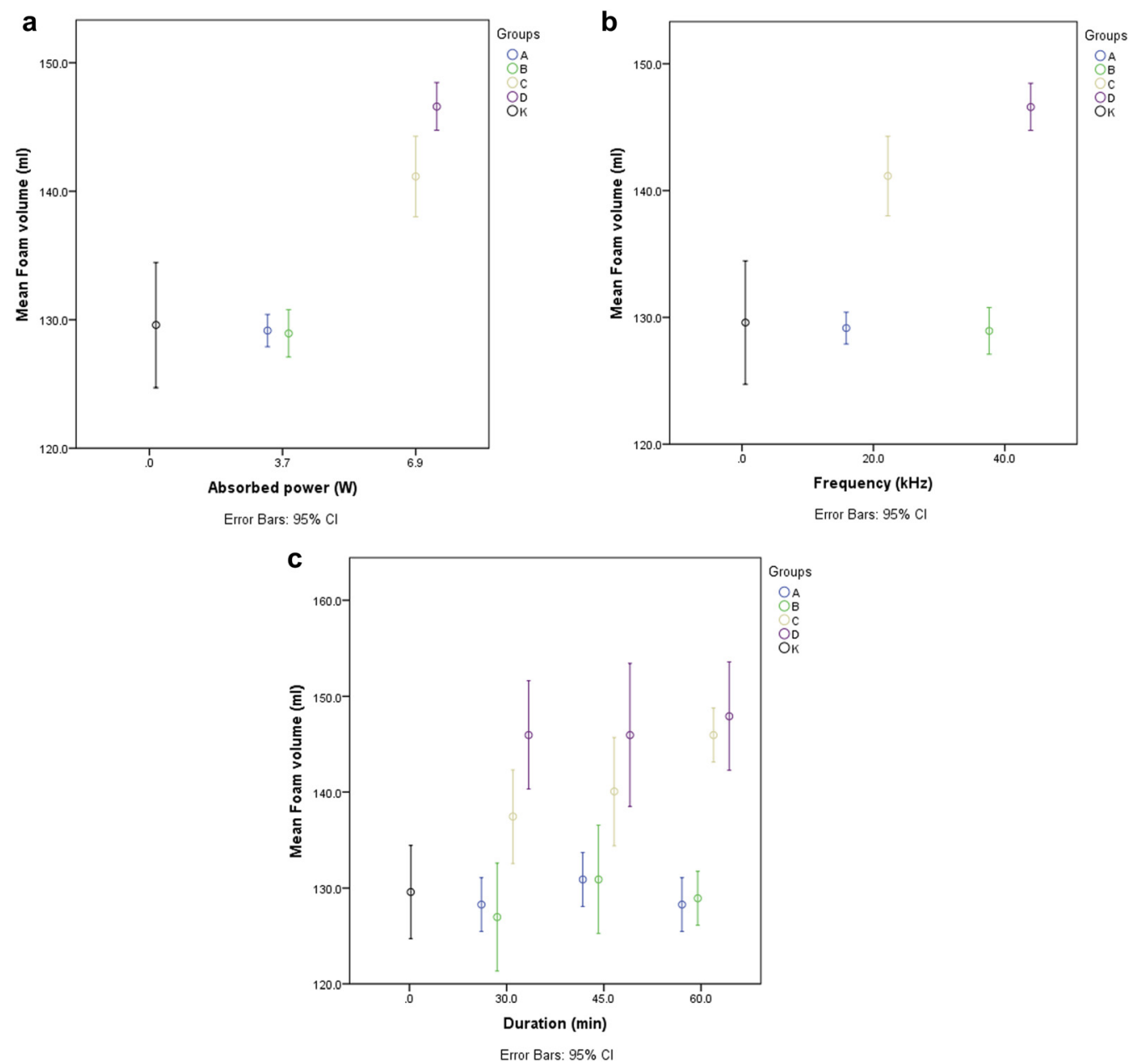

Fig. 2. Foam volume (mL) by absorbed power (a), frequency (b) and duration of the treatment (c). (A $3.7 \mathrm{~W}$ absorbed power and $20 \mathrm{kHz}$ frequency; $\mathrm{B}-3.7 \mathrm{~W}$ absorbed power and $40 \mathrm{kHz}$ frequency; $\mathrm{C}-6.9 \mathrm{~W}$ absorbed power and $20 \mathrm{kHz}$ frequency; D $-6.9 \mathrm{~W}$ absorbed power and $40 \mathrm{kHz}$ frequency)

In case of foam stability, data showed a decreasing trend due to sonication. Similarly to foam capacity, graphical analysis showed that the frequency and the duration of ultrasound treatment have no effect on this property, but the absorbed power has (Fig. 3). The Kruskal-Wallis test, however, showed that the frequency $(P=0.026)$ and the duration $(P=0.038)$ of the sonication treatment, besides the absorbed power $(P=0.000)$, have significant effect on foam stability.

These results also support the observation of previously reported studies (Chen et al., 2019; Sheng et al., 2018).

According to Stefanovic et al. (2017) the foaming stability has a linear relationship with the zeta potential of the egg white. We can assume that the sonication decreases the potential 

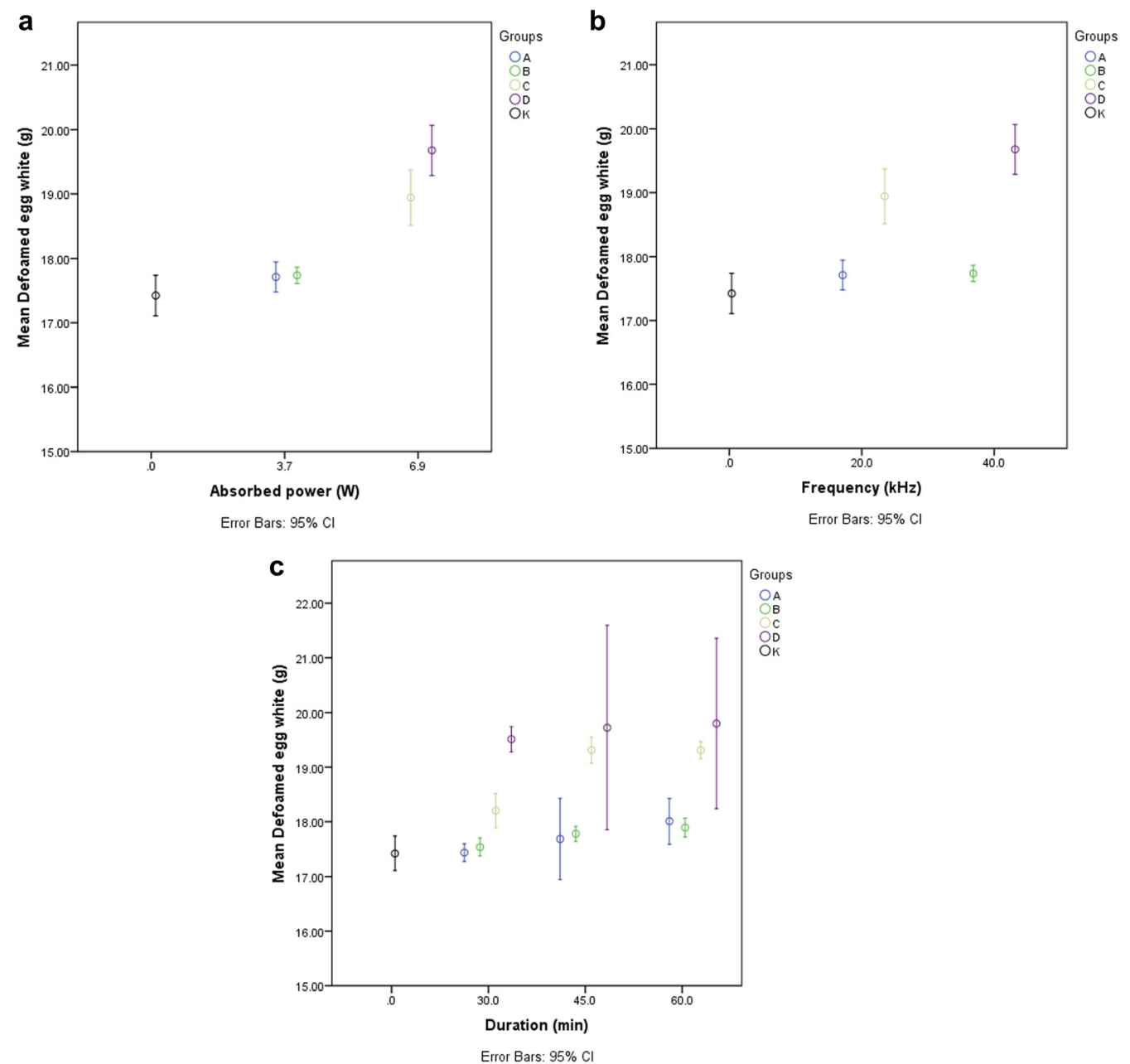

Fig. 3. Defoamed egg white (g) by absorbed power (a), frequency (b) and duration of the treatment (c) $(\mathrm{A}-3.7 \mathrm{~W}$ absorbed power and $20 \mathrm{kHz}$ frequency; $\mathrm{B}-3.7 \mathrm{~W}$ absorbed power and $40 \mathrm{kHz}$ frequency; $\mathrm{C}-6.9 \mathrm{~W}$ absorbed power and $20 \mathrm{kHz}$ frequency; D $-6.9 \mathrm{~W}$ absorbed power and $40 \mathrm{kHz}$ frequency)

difference between the dispersed particles (air) and the dispersion medium (egg white) and this may be the cause of the collapse of the foam structure due to ultrasound treatment.

\section{CONCLUSION}

In this study the effect of ultrasound treatment on the foam properties of egg white was examined. Foam capacity had been enhanced due to the sonication and a $25 \%$ increase was observed in the case of $40 \mathrm{kHz}$ and $300 \mathrm{~W}$ treatment with $60 \mathrm{~min}$ duration compared to control group samples. The foam stability, however, decreased. That may be caused by the changes in zeta potential of 
the egg white. In both cases, the power of the sonication had the biggest impact on the changes, and the frequency and duration had only affected the foam stability significantly.

The results supplied information about the applicability of ultrasound treatment in foam formation to achieve higher volume foam in the field of food processes.

\section{ACKNOWLEDGMENT}

The authors are grateful for the support of Capriovus Kft. (Szigetcsép, Hungary).

\section{REFERENCES}

Arzeni, C., Perez, O.E., and Pilosof, A.M.R. (2012). Functionality of egg white proteins as affected by high intensity ultrasound. Food Hydrocolloids, 29(2): 308-316. https://doi.org/10.1016/j.foodhyd.2012.03. 009.

Chen, Y., and Ma, M. (2020). Foam and conformational changes of egg white as affected by ultrasonic pretreatment and phenolic binding at neutral pH. Food Hydrocolloids, 102. https://doi.org/10.1016/j. foodhyd.2019.105568.

Chen, Y., Sheng, L., Gouda, M., and Ma, M. (2019). Impact of ultrasound treatment on the foaming and physicochemical properties of egg white during cold storage. LWT-Food Science and Technology, 113. https://doi.org/10.1016/j.lwt.2019.108303.

Duan, X., Li, J., Zhang, Q., Zhao, T., Li, M., Xu, X., and Liu, X. (2017). Effect of a multiple freeze-thaw process on structural and foaming properties of individual egg white proteins. Food Chemistry, 228: 243-248. https://doi.org/10.1016/j.foodchem.2017.02.005.

Hidas, K. I., Németh, C., Visy, A., Tóth, A., Friedrich, L. F., and Nyulas-Zeke, I. C. (2021). Comparison of different thawing methods effect on the calorimetric and rheological properties of frozen liquid egg yolk. Progress in Agricultural Engineering Sciences Progress, 16(S2): 37-44. https://doi.org/10.1556/446. 2020.20005.

Jambrak, A. R., Mason, T. J., Lelas, V., Herceg, Z., and Herceg, I. L. (2008). Effect of ultrasound treatment on solubility and foaming properties of whey protein suspensions. Journal Of Food Engineering, 86(2): 281-287. https://doi.org/10.1016/j.jfoodeng.2007.10.004.

Gelvez-Ordonez, V. M., Mendoza-Galvis, F., and Orlando Delgado, J. (2009). The effect of ultrasonic treatment on some functional properties of egg white. Revista Cientifica-Facultad De Ciencias Veterinarias, 19(1): 71-76, ISSN 0798-2259.

Mirmoghtadaie, L., Shojaee Aliabadi, S., and Hosseini, S. M. (2016). Recent approaches in physical modification of protein functionality. Food Chemistry, 199: 619-627. https://doi.org/10.1016/j. foodchem.2015.12.067.

Nagy, D., Felfoldi, J., Taczmanne Bruckner, A., Mohacsi-Farkas, C., Bodor, Z., Kertesz, I., Nemeth, C., and Zsom-Muha, V. (2021). Determining sonication effect on E. coli in liquid egg, egg yolk and albumen and inspecting structural property changes by near-infrared spectra. Sensors, 21(2). https://doi.org/10. 3390/s21020398.

Sheng, L., Wang, Y., Chen, J., Zou, J., Wang, Q., and Ma, M. (2018). Influence of high-intensity ultrasound on foaming and structural properties of egg white. Food Research International, 108: 604-610. https:// doi.org/10.1016/j.foodres.2018.04.007. 
Singh, A., and Ramaswamy, H. S. (2015). High pressure modification of egg components: exploration of calorimetric, structural and functional characteristics. Innovative Food Science \& Emerging Technologies, 32: 45-55. https://doi.org/10.1016/j.ifset.2015.09.010.

Stefanovic, A. B., Jovanovic, J. R., Dojcinovic, M. B., Levic, S. M., Nedovic, V. A., Bugarski, B. M., and Knezevic-Jugovic, Z. D. (2017). Effect of the controlled high-intensity ultrasound on improving functionality and structural changes of egg white proteins. Food and Bioprocess Technology, 10(7): 1224-1239. https://doi.org/10.1007/s11947-017-1884-5.

Open Access. This is an open-access article distributed under the terms of the Creative Commons Attribution 4.0 International License (https://creativecommons.org/licenses/by/4.0/), which permits unrestricted use, distribution, and reproduction in any medium, provided the original author and source are credited, a link to the CC License is provided, and changes - if any - are indicated. (SID_1) 